\title{
A FUNÇÃO DA TOMADA DE DECISÃO APOIADA EM UM CONTEXTO DE PANDEMIA
}

\section{Sara Bomfim Santa Rosa ${ }^{1}$}

RESUMO: Trabalho destinado a analisar a função da tomada de decisão apoiada quando inserida em um contexto pandêmico. Essa pesquisa é relevante para o âmbito social e jurídico, pois estuda esse instituto jurídico com o objetivo de sanar problemas gerados pela doença provocada pela COVID-19 à saúde humana. Este trabalho objetiva dialogar a tomada de decisão apoiada como uma ferramenta para tutelar vulnerabilidades a fim de efetivar a autonomia e o acesso à dignidade pelo paciente recuperado da infecção do novocoronavírus. A metodologia consiste em uma pesquisa bibliográfica e qualitativa com o uso do método dedutivo.

Palavras-chave: pandemia; tomada de decisão apoiada; sequelas; vulnerabilidade; COVID19

\section{THE ROLE OF SUPPORTED DECISION MAKING IN A PANDEMIC CONTEXT}

ABSTRACT: Work aimed at analyzing the function of supported decision making when inserted in a pandemic context. This research is relevant to the social and legal spheres, since it studies this legal institute with the objective of solving problems generated by the disease caused by COVID-19 to human health. This work aims to discuss supported decision making as a tool to protect vulnerabilities in order to enforce autonomy and access to dignity by the patient recovered from the novocoronavirus infection. The methodology consists of a bibliographic and qualitative research with the use of the deductive method.

Keywords: pandemic; supported decision making; sequels; vulnerability; COVID-19

\section{INTRODUÇÃO}

A temática deste artigo consiste em estudar uma possível relação entre o instituto jurídico civil da tomada de decisão apoiada e o contexto pandêmico, propondo o estabelecimento de uma conexão entre esses. Isso porque é importante possibilitar que pessoas recuperadas da doença causada pela COVID-19, contudo, possuidoras de sequelas geradas por esta enfermidade possam ter acesso pleno à dignidade por meio da tutela

\footnotetext{
1 *Mestra em Direitos Fundamentais e Alteridade pela Universidade Católica do Salvador (Ucsal). Advogada. Endereço postal: Rua. Alceu Amoroso Lima, 786 - Caminho das Árvores, cep nº. 41820-770, Sala 312, Salvador - BA Endereço eletrônico: adv.sarasantarosa@ gmail.com
} 
adequada de sua vulnerabilidade. Afinal, esta pode ser tão acentuada que pode mitigar a capacidade de autodeterminação do indivíduo.

O objetivo desta pesquisa é abordar a tomada de decisão apoiada enquanto ferramenta capaz de promover a autonomia do sujeito e o quanto esse instituto jurídico se revela necessário em tempos de pandemia, na medida em que a ciência médica tem convivido com um vírus pouco conhecido, portanto, que não se sabe com acuidade quais são as possíveis repercussões à saúde mental e física das pessoas recuperadas da infecção provocada por ele.

A justificativa desta pesquisa consiste na atualidade da importância da tomada de decisão apoiada para a sociedade, na medida em que qualquer indivíduo pode ser vítima do novocoranavírus, logo, pode vir a se tornar um paciente recuperado, entretanto, com sequelas que dificultem a prática de atos da vida civil patrimoniais e existenciais.

Este artigo é relevante também para a esfera científica, pois permite o diálogo entre a Medicina e o Direito com o objetivo de propor soluções que efetivem a dignidade da pessoa humana por meio da tutela da vulnerabilidade do indivíduo convalescido pela COVID-19.

O caminho metodológico deste artigo foi realizado por intermédio da pesquisa bibliográfica com natureza qualitativa e do método dedutivo.

Na primeira seção, elenca-se alguns conceitos sobre a tomada de decisão apoiada para alguns doutrinadores, bem como a sua função enquanto ferramenta jurídica. Além disso, afirma-se que a tomada de decisão apoiada se alinha à proposta da Convenção Internacional sobre os Direitos da Pessoa com Deficiência e das modificações geradas pelo Estatuto da Pessoa com Deficiência (EPD) ao Código Civil de 2002 (CC/02). Também evidencia que o instituto jurídico em questão deve se submeter aos tramites processuais, inclusive quanto à admissão ou supressão de apoiador.

$\mathrm{Na}$ segunda seção, aborda-se a vulnerabilidade da pessoa humana diante da pandemia provocada pelo novocoronavírus seja no âmbito físico, seja na esfera psicológica. Esse entendimento se dá em virtude da quantidade de estudos apontando possíveis repercussões da contaminação pela COVID-19 ao ser humano, tais como: problemas nos rins, coração, pulmão, quadros de ansiedade e depressão. Esta seção também discute a ideia da 
efetivação da dignidade por meio da proteção ou por intermédio da autonomia quando se pensa na tutela das vulnerabilidades de uma pessoa.

Na terceira seção, traz-se algumas razões para que haja a compreensão da possível função da tomada de decisão apoiada em um contexto pandêmico. Para tanto, aborda-se alguns estudos sobre as intercorrências que a COVID-19 pode gerar na integridade física e mental do ser humano. Defende-se também a relevância de que o grau de incidência da tomada de decisão apoiada seja proporcional à necessidade de auxílio para a realização dos atos da vida civil pelo indivíduo.

\section{A TOMADA DE DECISÃO APOIADA COMO INSTRUMENTO DE EFICÁCIA DA AUTONOMIA PRIVADA}

A tomada de decisão apoiada consiste em um instituto jurídico promovedor do empoderamento da pessoa vulnerável quando permite que esta escolha até dois amigos, familiares confiáveis para lhe auxiliar a decidir quanto aos atos da vida civil seja na seara patrimonial, seja no âmbito existencial. (REQUIÃO, 2016, p.43)

A autonomia, neste sentido, surge no ordenamento jurídico brasileiro sob a forma de um direito de personalidade, originado dos estudos em conjunto dos conceitos de saúde e liberdade. Daí porque, é necessário refletir acerca desses temas quando se pensa na tomada de decisão apoiada como possível solução jurídica para os "pacientes pós-covid". (BROCHADO, 2010, p. 1)

Verifica-se também que a tomada de decisão apoiada, no Brasil, não objetiva gerar perda da capacidade das pessoas acentuadamente vulneráveis, todavia reforçar a validade dos negócios jurídicos realizados por elas. (REQUIÃO, 2016, p.43)

O instituto jurídico mencionado acima surgiu no ordenamento jurídico com o objetivo de enaltecer a autonomia da pessoa, mesmo que esta se encontre em estado de vulnerabilidade proeminente. $\mathrm{O}$ indivíduo, portanto, não precisa necessariamente assistir à sua liberdade decisória acerca da sua vida ser substituída por uma curatela quando esta medida 
não for necessária para a promoção da sua dignidade. Afinal, há situações em que o nível de vulnerabilidade da pessoa não lhe retira completamente a sua capacidade, portanto, a sua autonomia. (ROSENVALD, 2018)

Em um Estado Democrático de Direito, o pluralismo é o sustentáculo de qualquer discussão, cujo objetivo seja fazer com que os debates caminhem na direção do reconhecimento de vulnerabilidades. Afinal, uma democracia promove a tutela das vulnerabilidades para garantir a efetivação da dignidade. A tomada de decisão apoiada, neste sentido, é uma expressão do diálogo entre ciência jurídica e democracia, na medida em que promove, ao máximo, a autonomia do indivíduo. (BROCHADO, 2010, p. 2)

A tomada de decisão apoiada se alinha à Convenção Internacional sobre os Direitos da Pessoa com Deficiência e com o direito fundamental à igualdade material, pois permite a tutela das vulnerabilidades das pessoas de forma diferente e proporcional à necessidade de cada uma delas. Afinal, há consenso sobre a vulnerabilidade humana, entretanto os indivíduos evidenciam a fragilidade que lhes é inerente em níveis distintos. (LARA, 2019, p. 39)

A vulnerabilidade humana deve ser compreendida, então, como o meio pelo qual as pessoas podem ser livres para desenvolverem-se quando o grau de fragilidade permite um auxílio e não uma substituição de vontade como pode ser o caso de pacientes recuperados da COVID-19.

É relevante frisar que a tomada de decisão apoiada possui todo o respaldo do Direito, tendo, portanto, que se submeter ao sistema processual e aos seus atos, tais como: a possibilidade de ouvir o Ministério Público quando a opinião do apoiado e do apoiador divergirem sobre alguma temática com potencial para trazer risco relevante ao apoiado. É possível também que um dos apoiadores não deseje mais exercer essa função ou que o apoiado queira destituir um dos seus auxiliadores, evidenciando-se, portanto, o caráter de voluntariedade e de confiança do instituto jurídico civil ora abordado. (REQUIÃO, 2016, p.44)

Nelson Rosenvald compreende a tomada de decisão apoiada como a expressão de uma menor incidência da curatela, por meio do estudo pormenorizado do projeto terapêutico do indivíduo. Com isso, do suporte jurídico suficiente para acolher a sua vulnerabilidade sem lhe retirar a parcela de autonomia que lhe caiba. (ROSENVALD, 2018, p. 105) 
Defende-se, portanto, que toda pessoa humana é um sujeito moral, logo, possui liberdade para atuar de acordo com a sua moralidade. Para tanto, porém, não se pode sacrificar o direito à igualdade. A autodeterminação, então, precisa caminhar junto à igualdade a fim de que a dignidade da pessoa humana seja alcançada. (MENEZES, 2016, p. 36-37)

A autonomia da pessoa humana deve ser exercida na proporção do seu discernimento quanto às ações que pratica enquanto titular do direito, podendo ser possibilitada pela tomada de decisão apoiada, por exemplo. (BROCHADO, 2010, p. 5)

O instituto jurídico supracitado revela ser um instrumento do Direito importante quando tutela pessoas que estão impossibilitadas de exercerem os seus direitos civis, políticos, econômicos, sociais e culturais e, desta forma, possuem dificuldade para decidir no que concerne à sua saúde, educação e trabalho. A tomada de decisão apoiada, assim, promove igualdade material quando verifica a diminuição da capacidade de autodeterminação do indivíduo, possibilitando a efetivação do princípio da dignidade da pessoa humana. (ROSENLVALD, 2018, p. 108)

Além da discussão acerca da autonomia do sujeito dentro da esfera jurídica estar entrelaçada com o debate acerca da autonomia da pessoa no âmbito bioético, a concepção de solidariedade também soma à contribuição da Bioética na ideia da utilização da tomada de decisão apoiada em contexto pandêmico. Esse entendimento se dá, pois a vulnerabilidade é intrínseca ao ser humano, portanto, a solidariedade se torna condição basilar da Humanidade, haja vista a falibilidade universal inerente à espécie humana e a possibilidade dessa fragilidade se avolumar diante de um acontecimento aleatório, a exemplo da contaminação por um vírus mortal. (NOGUEIRA; SOUZA, 2019, p.180)

Neste contexto, salienta-se que o artigo 114 do Estatuto das Pessoas com Deficiência (EPD) objetivou a mudança da norma jurídica disposta no Código Civil de 2002 (CC/02) acerca da classificação dos absolutamente e relativamente incapazes.

O EPD, neste contexto, descreveu que apenas os menores de 16 anos são desprovidos de toda a capacidade para os atos da vida civil, bem como que um dos critérios para ter a sua capacidade relativizada é estar diante de um motivo transitório ou permanente que inviabilize a exposição da sua vontade. 
Frequentemente, a negação da capacidade jurídica das pessoas com deficiência priva-lhes de vários direitos fundamentais, como o direito ao voto, o direito ao matrimônio e ao estabelecimento de família, os direitos reprodutivos, o direito à autoridade parental, o direito ao consentimento ao tratamento médico e o direito à liberdade. (ROSENVALD, 2018, p. 108)

Defende-se que a tomada de decisão apoiada, disposta no artigo 1783-A do CC/02, permite a promoção da dignidade de pessoas relativamente incapazes pela razão supracitada, uma vez que possibilita ao indivíduo concluir que está com a sua autonomia mitigada e, desta forma, mais vulnerável, portanto, carecendo de ajuda para expressar os seus desejos.

Conforme Roberto Henrique Nogueira e Iara Antunes Souza, então, as "vulnerabilidades parecem marcar ou contribuir sobremaneira para a identificação de novos". Essa assertiva se torna evidente quando se pensa na tomada de decisão apoiada e na intensidade da sua importância para a resolução de problemáticas oriundas justamente da fragilidade da vida humana, tais como as geradas por sequelas da doença provocada pelo novocoronavírus. (NOGUEIRA; SOUZA, 2019, p.181)

É importante frisar que discutir a possibilidade da tomada de decisão apoiada ser um sustentáculo da autonomia de pacientes recuperados da doença provocada pela SARS-COV-2 é de extrema relevância para o poder público, na medida em que a "Constituição Federal de 1988 qualificou expressamente o direito à saúde como direito social”, tendo portanto, um viés prestacional. Para se estar saudável, por sua vez, é preciso ter bem-estar, o qual só pode ser obtido por meio da tutela da vulnerabilidade do Outro a fim de que este possa alcançar a plenitude proposta pela dignidade da pessoa humana. Alinha-se, assim, saúde e liberdade. (BROCHADO, 2010, p. 16)

\section{A VULNERABILIDADE FÍSICA E PSICOLÓGICA DO SER HUMANO EM VIRTUDE DA PANDEMIA DA COVID-19}

A tomada de decisão apoiada não retira a capacidade civil da pessoa, apenas evidencia uma majoração da sua vulnerabilidade. Além disso, o instituto jurídico em questão deve possuir prazo de validade justamente para garantir que não seja compreendido como 
uma curatela, isto é, algo permanente, haja vista a situação de fragilidade na qual a pessoa está inserida não inspira interdição, mas auxílio. (MENEZES, 2016, p. 49)

Ao refletir acerca da tomada de decisão apoiada ora exposta e a vulnerabilidade física e psicológica do ser humano diante da pandemia, percebe-se que é possível que um paciente recuperado da COVID-19, por exemplo, desenvolva um quadro clínico de fibrose pulmonar irreversível, mesmo que se realize fisioterapia.

Pode-se, então, compreender o quanto o paciente do exemplo supracitado estaria vulnerável fisicamente e psicologicamente, o que evidencia a necessidade de que ele tenha um apoio confiável para tomar decisões acerca da sua própria existência, principalmente quanto aos seus interesses existenciais. Isso porque estes "sempre motivaram um plexo significativo de temas jurídicos por estarem visivelmente assentadas na necessidade de avaliar a medida adequada de incidência da autonomia privada”. (MEIRELES; AGUIAR, 2017, p.716)

Ludhmilla Hajjar -cardiologista e professora da Universidade de São Paulo (USP)-, inclusive, afirma que "é possível que 10 a 20\% dos entubados evoluam com necessidade permanente de oxigênio", sendo assim esse paciente provavelmente ficará impossibilitado de decidir sobre as suas próprias ações com a mesma acuidade que deliberava antes da doença gerada pela novocornavírus. Isso porque a sua capacidade respiratória estaria prejudicada, assim como sentiria fadiga, dores musculares, o que poderia produzir ansiedade, depressão. (PINHEIRO, 2020)

A vulnerabilidade humana deve ser respeitada enquanto princípio ético conforme determina a Declaração Universal de Bioética e Direitos do Homem da UNESCO, aprovada no mês de outubro do ano de 2005. Maria do Céu Patão Neves, neste sentido, afirma que vulnerabilidade consiste na possibilidade de ser ferido, isto é, na capacidade que a pessoa humana tem de ser maculada em sua autonomia. Esta situação, por sua vez, pode ocorrer tanto diante de uma conduta racista, sexista como em decorrência de uma doença, acidente que mitigue a possibilidade de autodeterminação do indivíduo. (NEVES, 2007)

Ludhmilla Hajjar, neste sentido, assevera que "as sequelas mais prolongadas são observadas em pessoas com versões severas da doença, que desenvolvem a tal tempestade inflamatória", a qual consiste em excesso de substâncias que danificam o organismo humano ao invés de expurgar o vírus. (PINHEIRO, 2020) 
Entende-se, portanto, que "todos os humanos são, por natureza, vulneráveis, visto que todos os seres humanos são passíveis de serem feridos, atingidos em seu complexo psicofísico", contudo essa fragilidade se expressa de forma e com incidência distinta, mesmo que os indivíduos estejam vivenciando a mesma circunstância. Esse entendimento se sustenta na ideia de que pessoalidades podem intervir agravando a susceptibilidade da pessoa humana a ser vulnerável. (BARBOZA, 2009, p. 107)

Pensar, por exemplo, em um paciente que conseguiu ser internado assim que começou a sentir falta de ar e em um enfermo que ficou horas, dias esperando ter vaga em uma UTI para, então, se submeter ao procedimento médico necessário possibilita a compreensão de que provavelmente o pulmão do primeiro estará mais preservado do que o do segundo. Assim sendo, este paciente estará mais vulnerável do que aquele, caso ambos sobrevivam, quando se pensa em intercorrências geradas pela covid-19 no organismo humano.

É provável também que a SARS-COV-2 seja uma ameaça para os rins e para o coração, gerando insuficiência cardíaca e renal, sendo que "quanto aos rins, até $40 \%$ das pessoas que vão para a UTI sofrem com insuficiência renal e precisam de hemodiálise durante a internação", precisando de 3 meses para a recuperação regra geral. (PINHEIRO, 2020)

Diante do exposto, constata-se que a "subjetividade humana é bem mais complexa do que um catálogo de regras jurídicas e nada melhor que um pouco de delicadeza no trato do semelhante" e os institutos jurídicos existem para diminuir as intercorrências da vida, inclusive na esfera da saúde tanto física quanto psicológica, uma vez que ambas precisam caminhar no mesmo compasso para que se alcance bem-estar. As sequelas do novocoronavírus, portanto, devem ser administradas juridicamente nesses dois contextos. (ROSENLVALD, 2018, p. 122)

\footnotetext{
Pesquisas anteriores à crise atual mostram, por exemplo, que até $20 \%$ dos indivíduos afetados pela Síndrome Respiratória Aguda Grave (SRAG), uma das complicações que a COVID-19, a gripe e outras infecções podem provocar, apresentam déficits cognitivos até cinco anos depois da alta. Entre eles, além da dificuldade de raciocínio e memória prejudicada surgem sintomas de ansiedade, depressão, estresse pós-traumático etc. (PINHEIRO, 2020)
}

Ana Carolina Brochado destaca que todas as pessoas, independente do que projetam para si, "têm igual valor para o Direito, pois o que mudou foi que o indivíduo passou a ter 
importância pelo simples fato de ser pessoa, que pode elaborar seus projetos e viver segundo as próprias concepções, com as próprias singulares". Essa compreensão é tão relevante para a ciência jurídica que esta criou a tomada de decisão apoiada justamente para que as pessoas que não precisassem ser demasiadamente tolhidas de sua capacidade decisória pudessem exprimir as suas vontades, mesmo que por intermédio de duas ou mais pessoas gozadoras da sua confiança. (BROCHADO, 2018, p. 77)

É necessário também refletir acerca da relação que existe entre o avanço pandêmico e o problema de saúde pública gerado pelo cuidado biopsicossocial com os recuperados, porque o sistema de saúde pode não conseguir absorver a demanda de pessoas que precisa tratar das sequelas provocadas pela COVID-19 ao seu corpo e à sua mente. (PINHEIRO, 2020)

Sustenta-se, então, que a circunstância mencionada acima pode incidir em um aumento de tempo do "paciente pós-covid", tendo que se utilizar da tomada de decisão apoiada para ter acesso efetivo à uma vida digna. Isso porque "onde a autonomia se vê diminuída, a proteção deve ter lugar. Só assim o sujeito será verdadeiramente incluído na sociedade, objetivo primordial do Estatuto da Pessoa com Deficiência”. (LARA, 2019, p. 61)

A SARS-COV-2 também é devastadora em quadros clínicos menos gravosos, havendo constatações científicas de desenvolvimento de inclinação ao diabetes em pacientes que não possuíam essa doença, desenvolvendo, inclusive, alterações no pâncreas. Outros enfermos podem apresentar a Síndrome de Guillain Barré, o que gera paralisia em todo o corpo. (PINHEIRO, 2020)

Neste contexto, afirma-se que a tomada de decisão apoiada pode ser uma ferramenta a ser utilizada por anciãos "drogaditos ou alcóolicos, pessoas que tenham dificuldade para locomoção, limitadas por sequelas de acidente vascular cerebral ou aquelas que estão nas fases iniciais de doença de Alzheimer, além daquelas que tem alguma deficiência física, psíquica ou intelectual”, gerada, por exemplo, em virtude da COVID-19. (MENEZES, 2016, p. 46)

Ante a omissão legal, o apoio pode se estabelecer quanto às questões patrimoniais e/ou às questões existenciais, nada impedindo que também incida sobre decisões da rotina doméstica ou pertinentes aos cuidados pessoais. O tipo do apoio também pode ser de ordem variada, a depender da necessidade específica de quem o requer. Pode 
consistir na facilitação da comunicação, na prestação de informação e esclarecimentos, no auxílio à análise dos fatores favoráveis e desfavoráveis que circundam certa decisão etc., tudo a depender do caso específico e das demandas da pessoa que precisa do apoio. (MENEZES, 2016, p. 47)

O grupo A Tarde comunicação entrevistou alguns pacientes recuperados da COVID19, os quais relataram as repercussões médicas do vírus em seu organismo, tais como: tremores, ausência de forças nos braços e nas pernas, além de agravação da crise asmática meses após a infecção. (SANTANA, 2021)

Ficar internado durante dias, semanas pode gerar o sentimento de solidão nos pacientes conscientes ou de falta de memória nas pessoas que precisam ser entubadas e sedadas. Podem haver pacientes que estão se submetendo ao procedimento de entubação com níveis menores de sedação, acordam e se incomodam com o aparelho. É perceptível que essas situações geram medo quanto ao processo de evolução da enfermidade, desencadeando provavelmente problemas psicológicos caso sobrevivam à doença causada pelo SARS-COV2.

A tomada de decisão apoiada objetiva justamente retirar a pessoa, com maior grau de vulnerabilidade física ou psicológica, da posição de proteção demasiada, evidenciada quando se pensa que esse indivíduo acentuadamente vulnerável terá de se abster completamente da autonomia, mesmo que essa decisão não seja tão necessária quanto se pensa para ter acesso à dignidade. Intenciona-se, portanto, retirar a pessoa do paradigma dignidade-proteção para elevá-la ao de dignidade-autonomia quando for possível não interditar o indivíduo. Essa permissão é dada, por exemplo, pela Medicina e pela Psicologia, afinal são estas áreas do conhecimento que atestam a saúde física e mental das pessoas, portanto o quão vulneráveis elas realmente estão diante de um fato. (LIMA; VIEIRA; SILVA, 2017, p.17)

Embora os estudos acerca das sequelas deixadas pela doença causada pela COVID19 sejam poucos, eles já apontam que as repercussões à saúde das pessoas vão além, da fadiga - cansaço persistente-. As sequelas, inclusive, podem ser vivenciadas por pacientes com sintomas escassos ou assintomáticos. Algumas dessas repercussões pós covid-19 são: perda do olfato, do paladar, episódios de psicose, doenças autoimune, artralgias, artrites. (UZUN, 2020) 


\section{A FUNÇÃo dA TOMAdA DE DECISÃo APOIADA EM UM CONTEXTO DE PANDEMIA}

Percebe-se que "não há como desconstruir a realidade inerente à imperfeição humana e às vicissitudes que a todos afetam em maior ou menor grau. Em um Estado Democrático de Direito, o pluralismo demanda o respeito pelas diferenças e não de seu aniqualamento". É relevante, então, apostar na tomada de decisão apoiada como uma ferramenta de preservação da autodeterminação remanescente da pessoa, embora esta precise de sustentação amigável de outra para decidir sobre questões patrimoniais e existenciais. (ROSENLVALD, 2018, p. $110 ; 118)$

Neste contexto, assevera-se que o Estatuto da Pessoa com Deficiência aduz que as pessoas só são consideradas relativamente capazes para os atos da vida civil quando elas não conseguem expressar qualquer vontade diante da severidade do seu quadro clínico, caso contrário são compreendidas como plenamente capazes para decidirem sobre suas vidas, inclusive sobre quem será responsável por lhe auxiliar a exercer a sua capacidade jurídica se vier a vivenciar sequelas de uma doença. (LARA, 2019, p.41;45)

A tomada de decisão apoiada, portanto, consiste em uma medida visando o equilíbrio, por meio da supressão pontual da autonomia da pessoa a fim de que os indivíduos tenham igualdade material, assim a ferramenta jurídica em questão consiste em uma “oportunidade para as pessoas com algum impedimento de natureza física, mental, intelectual ou sensorial" terem uma vida digna. (LARA, 2019, p. 54)

Ter um representante não significa, necessariamente,estar diminuído em sua
dignidade. A representação voluntária bem demonstra que ter um representante que
respeite a vontade e os desejos do representado é uma forma de exercício da
autonomia e de resguardo dos próprios interesses. Transpondo essa ideia para a
representação legal, sempre como medida excepcional, proporcional e adequada ao
caso, respeitando a autonomia que ainda resta ao indivíduo, haverá respeito à
dignidade da pessoa com discernimento reduzido. (LARA, 2019, p. 60)

Dentro deste prisma, aborda-se que o portal "Saúde debate" trouxe a história de Cristiane Barbieri, uma ex paciente de COVID-19 de 40 anos, que esteve internada por 22 dias e, portanto, teve que fazer tratamentos para as mazelas deixadas pela doença em seu 
organismo, tais como: problemas no fígado, trombose, arritmias, infartos, acidente vascular cerebral (AVC), ansiedade e distúrbios do sono.

A tomada de decisão apoiada será de acordo com a necessidade da pessoa ser auxiliada, na medida em que os indivíduos são distintos e, desta forma, precisam de apoios diferentes. Quando se pensa, por exemplo, nas mazelas geradas pelo novocoronavírus na saúde física e mental da pessoa, deve-se refletir acerca do grau das sequelas a fim de que se possa decidir com mais acuidade sobre a incidência do instituto jurídico em questão na vida do enfermo recuperado da SARS-COV-2. (MENEZES, 2016, p. 39)

Um estudo realizado pela Universidade Federal de Minas Gerais (UFMG) aponta que há sintomas que podem persistir por meses ou anos, concluindo que embora a pesquisa ainda esteja em fase inicial investigativa, "é possível que algumas sequelas da COVID-19 identificadas nesse primeiro grupo de pacientes persistam por até dois anos" caso a COVID19 se comporte de maneira semelhante à Síndrome Respiratória Aguda Grave (SARS) "doença causada por agente da mesma família do coronavírus, identificada em 2002-". (UFMG, 2021)

Uma pesquisa publicada na última semana no periódico médico Jama Network mostrou que $30 \%$ dos participantes ainda relatavam sintomas nove meses após contrair o vírus. A maior parte dos indivíduos acompanhados pelo estudo tiveram casos leves da doença. (SATIE, 2021)

Outros estudos apontam que a contaminação pela COVID-19 pode gerar erupções na pele. Dermatologistas têm asseverado que a lesão, inclusive, pode ser o único sintoma de que a pessoa teve contato com o novocoronavírus. Registre-se que "essas informações foram reunidas por pesquisadores do King's College London, no Reino Unido, em um estudo com base em informações coletadas de quase 350 mil pessoas", das quais $17 \%$ afirmaram que as erupções foram um dos sintomas vivenciados e $21 \%$ disseram que as lesões na pele consistiram no único sintoma da infecção pela COVID-19. (MARTINS, 2021, p.2)

É relevante apontar também que não há descobertas científicas acerca do que a contaminação da COVID-19 pode provocar no organismo humano a longo prazo, mas existem estudos que trazem como prováveis consequências da enfermidade causada pelo novocoronavírus: infartos, insuficiência renal, cardíaca, transtornos psiquiátricos. (SATIE, 2021) 
Sustenta-se, diante do exposto, que a tomada de decisão apoiada pode ser requerida por qualquer pessoa, todavia essa ferramenta jurídica de promoção da dignidade humana "é mais indicada para aquelas pessoas que têm capacidade jurídica e sofrem alguma dificuldade para realizar certas escolhas devido a uma deficiência intelectual ou psíquica, aos efeitos de uma lesão cerebral, à deficiência psicossocial ou à idade avançada”. É interessante, então, que as sequelas da COVID-19 podem ensejar a decisão do indivíduo pela utilização da tomada de decisão apoiada a seu favor para, assim, diminuir o aumento da sua vulnerabilidade e, com isso, garantir a sua dignidade. (MENEZES, 2016, p. 31)

A tomada de decisão apoiada surge, logo, com uma proposta de emancipação para garantir a dignidade, afinal "a representação por substituição de vontade é prejudicial ao exercício e ao gozo de certos direitos fundamentais". Isso porque existem direitos que impossibilitam a cisão entre capacidade de exercício e capacidade de gozo, a exemplo do matrimônio, do planejamento familiar, da liberdade religiosa. (MENEZES, 2016, p. 34)

\section{CONSIDERAÇÕES FINAIS}

O presente artigo abordou a tomada de decisão apoiada enquanto possibilidade jurídica para garantir o acesso dos pacientes recuperados da COVID-19 à dignidade, por intermédio da tutela de suas vulnerabilidades na medida necessária a fim de que a pessoa possa exercer a autodeterminação de que for possível.

Esta pesquisa objetivou tratar sobre a tomada de decisão jurídica como instituto jurídico pré-existente à pandemia que pode possibilitar que os enfermos "pós-covid" sejam capazes de decidir quanto aos atos da vida civil tanto do ponto de vista patrimonial quanto do existencial.

Este artigo se mostrou relevante, pois possibilitou que a comunidade científica enxergasse um caminho dentro do ordenamento jurídico capaz de promover a dignidade da pessoa humana, exaltando a autonomia do indivíduo e não a sua proteção elevada.

Os artigos e as notícias acessados possibilitaram compreender o quanto ainda se 
pensa sobre as possíveis intercorrências médicas e psicológicas da doença causada pela SARS-COV-2 à mente e ao corpo humano.

Constatou-se que a tomada de decisão apoiada pode ser uma ferramenta jurídica para solucionar a problemática perspectivada pela Bioética e pela Medicina quanto a possíveis sequelas vivenciadas pelo ser humano em seu organismo, tais como: intercorrências cardíacas, renais, pancreáticas, ansiedade, depressão, perda de memória.

O entendimento acima se sustenta no fato de que um indivíduo, vivenciando repercussões do novocoronavírus em seu organismo, pode não se sentir apto para decidir acerca dos atos da vida civil sozinho e, desta forma, desejar ter duas ou mais pessoas confiáveis para lhe prestar auxílio diante da sua vulnerabilidade.

Frise-se que caso o paciente recuperado da COVID-19 não consiga, porém, expressar a sua vontade em grau algum, então ela não poderá utilizar a tomada de decisão apoiada, pois não haverá capacidade de se autodeterminar diante da sua vulnerabilidade exacerbada. Neste caso, portanto, caberia um pedido de curatela, pois seria a única maneira, mesmo que bastante protetiva, de garantir a essa pessoa o acesso a uma vida digna.

A dignidade da pessoa humana, então, deve ser o objetivo primordial e o alcance desta por meio da promoção da autonomia precisa ser a regra, a exemplo da utilização da tomada de decisão apoiada por pacientes recuperados da COVID-19, contudo, portadores de sequelas da doença provocada por este vírus. Se compreende, todavia, que há situações que conclamam um viés protetivo em decorrência da fragilidade que a pessoa vivencia. Pensar dessa forma não desumaniza o ser humano, pelo contrário, o torna mais consciente da sua vulnerabilidade diante das vicissitudes da vida.

\section{REFERÊNCIAS}

BARBOZA, Heloísa Helena. Vulnerabilidade e cuidado: aspectos jurídicos. In: Pereira, T.S.; Oliveira, G. (coord). Cuidado e Vulnerabilidade. São Paulo: Atlas, 2009. 
BRASIL. Lei no 13.146, de 6 de julho de 2015. Institui a Lei Brasileira de Inclusão da Pessoa com Deficiência (Estatuto da Pessoa com Deficiência). Disponível em: http://www.planalto.gov.br/ccivil_03/_ato2015-2018/2015/lei/113146.htm. Acesso em: 20 mar. 2021.

BRASIL. Lei $\mathbf{n}^{\mathbf{0}}$ 10406, de 10 de janeiro de 2002. Institui o Código Civil. Disponível em: http://www.planalto.gov.br/ccivil_03/leis/2002/L10406compilada.htm. Acesso em: 16 mar. 2021.

BROCHADO, Ana Carolina. Autonomia Existencial. Revista Brasileira de Direito Civil RBDCivil, Belo Horizonte, v. 16, abril-junho. 2018, p. 75-104. Disponível em: https://rbdcivil.ibdcivil.org.br/rbdc/article/view/232. Acesso em: 03 fev. 2020.

BROCHADO, Ana Carolina Teixeira. Saúde, Corpo e Autonomia Privada. Rio de janeiro: Renovar, 2010.

Faculdade de Medicina da UFMG. Dor, depressão e ansiedade podem estar entre as sequelas da Covid-19, 08 set. 2020. Disponível em: https://www.medicina.ufmg.br/dordepressao-e-ansiedade-podem-estar-entre-as-sequelas-da-covid-19/. Acesso em: 18 mar. 2021.

LARA, Mariana. Em defesa da restauração do discernimento como critério para a incapacidade de fato. Revista Brasileira de Direito Civil - RBDCivil, Belo Horizonte, v. 19, jan/mar 2019, p. 39-61. Disponível em: https://rbdcivil.ibdcivil.org.br/rbdc/issue/view/22. Acesso em: 15 mar. 2021

LIMA, Taisa Maria; VIEIRA, Marcelo; SILVA, Beatriz. Reflexões sobre as pessoas com deficiência e sobre os impactos da lei no 12.146/2015 no estudo dos planos do negócio jurídico. Revista Brasileira de Direito Civil (RBDCivil), Belo Horizonte, v. 14, out-dez 2017, p.17-39. Disponível em: https://rbdcivil.ibdcivil.org.br/rbdc/article/view/164. Acesso em: 20 mar. 2021

MARTINS, Cristiane. 'Efeitos da COVID': 21\% dos infectados por Coronavírus relataram só problemas de pele, diz estudo; Lesões não devem ser ignoradas. Revista Época. 28 mar. 2021, p.1-14. Disponível em: https://epoca.globo.com/sociedade/efeitos-da-covid-21-dos- 
infectados-por-coronavirus-relataram-so-problemas-de-pele-diz-estudo-lesoes-nao-devemser-ignoradas-1-24945063. Acesso em: 29 mar. 2021.

MEIRELES, Ana Thereza. AGUIAR, Mônica. Prática médica e diretivas antecipadas de vontade: Uma análise ético-jurídica da conformação harmônica entre os pressupostos autonomia e alteridade. Revista Jurídica Cesumar v. 17, n. 3, setembro-dezembro 2017, p. 715-739. Disponível em:

http://periodicos.unicesumar.edu.br/index.php/revjuridica/article/view/5686. Acesso em: 11 ago. 2019.

MENEZES, Joyceane. Tomada de decisão apoiada: instrumento de apoio ao exercício da capacidade civil da pessoa com deficiência instituído pela lei brasileira de inclusão (Lei ${ }^{\circ}$ 13.136/2015). Revista Brasileira de Direito Civil (RBDCivil), Belo Horizonte, v. 8, jul-set 2016, p. 31-57. Disponível em: https://rbdcivil.ibdcivil.org.br/rbdc/article/view/53/47. Acesso em: 19 mar. 2021

NEVES, Maria do Céu. Sentidos da Vulnerabilidade: característica, condição, princípio, 2007. Disponível em:

https://www.researchgate.net/publication/285916547_Sentidos_da_vulnerabilidade_caracteris

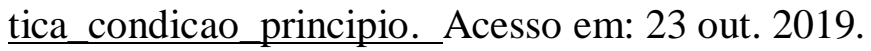

NOGUEIRA, Roberto Henrique; SOUZA, Iara. Pessoa com deficiência: O Direito ao casamento a partir da abordagem das vulnerabilidades. XXVIII Congresso Nacional do CONPEDI, Belém- PA, 2019, p. 177-194. Disponível em: http://conpedi.danilolr.info/publicacoes/048p2018/wh5rju9z. Acesso em: 17 nov.2020. PINHEIRO, Chloé. Além da falta de ar: sequelas que o coronavírus pode deixar após a cura. Revista Veja, 15 jun. 2020, p.1-5. Disponível em: https://saude.abril.com.br/medicina/alemda-falta-de-ar-sequelas-que-o-coronavirus-pode-deixar-apos-a-cura/. Acesso em: 17 mar. 2021.

PORTAL SAÚDE DEBATE. Sequelas da COVI-19: a vida não voltou ao normal após a alta hospitalar, 13 nov. 2020, p.1-9. Disponível em: https://saudedebate.com.br/noticias/sequelasda-covid-19-a-vida-nao-voltou-ao-normal-apos-a-alta-hospitalar Acesso em: 17 mar. 2021. 
ROSENVALD, Nelson. A curatela como a terceira margem do rio. Revista Brasileira de Direito Civil - RBDCivil, Belo Horizonte, v. 16, abr/jun 2018, p. 105-123. Disponível em: https://rbdcivil.ibdcivil.org.br/rbdc/article/view/233. Acesso em: 15 mar. 2021

SANTANA, Raphael. Pacientes recuperados da Covid-19 relatam sequelas; quadros podem ser irreversíveis. Grupo A Tarde, 15 out. 2020, p.1-4. Disponível em:

https://coronavirus.atarde.com.br/covid-19-pacientes-recuperados-relatam-sequelas-dadoenca-especialistas-dizem-que-quadros-podem-ser-permanentes/. Acesso em: 16 mar. 2021.

SATIE, Anna. Sequelas da Covid-19 podem persistir por longo prazo até em casos leves.

CNN Brasil, 25 fev. 2021, p.1-3. Disponível em:

https://www.cnnbrasil.com.br/saude/2021/02/25/sintomas-da-covid-19-podem-persistir-porlongo-prazo-ate-em-casos-leves. Acesso em: 19 mar. 2021.

UZUN, Ana Cristina. Sequelas da COVID-19 vão além da fadiga, ressalta especialista. Portal do Governo de Mato Grosso do Sul, 18 dez. 2020, p.1-6. Disponível em:

https://www.saude.ms.gov.br/sequelas-da-covid-19-vao-alem-da-fadiga-ressalta-especialista/. Acesso em: 16 mar. 2021. 